\title{
Adrenocortical tumors in children
}

\author{
R.C. Ribeiro ${ }^{1,2,3}$, \\ E.L. Michalkiewicz ${ }^{1,4}$, \\ B.C. Figueiredo $0^{5}$, \\ L. DeLacerda ${ }^{5}$, F. Sandrini ${ }^{5}$, \\ M.D. Pianovsky ${ }^{6}$, \\ G. Sampaio ${ }^{7}$ and R. Sandrini ${ }^{5}$
}

\begin{abstract}
'Department of Hematology-O ncology, 2 International O utreach Program, St. Jude Children's Research Hospital, and ${ }^{3}$ D epartment of Pediatrics, College of Medicine, U niversity of Tennessee, Memphis, TN, USA ${ }^{4}$ Departamento de Cirurgia Pediátrica, Hospital Erasto Gaertner, Curitiba, PR, Brasil ${ }^{5}$ Departamento de Pediatria, ${ }^{6}$ Divisão de Endocrinologia, Hematologia/O ncologia and ${ }^{7}$ Departamento de Patologia, Hospital das Clínicas, Curitiba, PR, Brasil
\end{abstract}

\author{
Correspondence \\ R.C. Ribeiro \\ Department of Hematology-O ncology \\ St. Jude Children's Research \\ Hospital \\ 332 North Lauderdale \\ Memphis, TN 38105 \\ USA \\ Fax: + 1-901-495-3122 \\ E-mail: raul.ribeiro@stjude.org \\ Presented at the First \\ International M eeting on Adrenal \\ Disease: Basic and Clinical \\ Aspects, Ribeirão Preto, SP, Brazil, \\ August 31-September 2, 1999. \\ Research supported in part by \\ the National Cancer Institute (Nos. \\ P30 CA-21765 and PO 1 CA-20180) \\ and by the American Lebanese Syrian \\ Associated Charities (ALSAC).
}

Received December 20, 1999 Accepted June 14, 2000

\section{Abstract}

Childhood adrenocortical tumors (ACT) are rare. In the USA, only about 25 new cases occur each year. In Southern Brazil, however, approximately 10 times that many cases are diagnosed each year. Most cases occur in the contiguous states of São Paulo and Paraná. The cause of this higher rate has not been identified. Familial genetic predisposition to cancer (p53 mutations) and selected genetic syndromes (Beckwith-Wiedemann syndrome) have been associated with childhood ACT in general but not with the Brazilian counterpart. Most of the affected children are young girls with classic endocrine syndromes (virilizing and/or Cushing). Levels of urinary 17-ketosteroids and plasma dehydroepiandrosterone sulfate (DHEA-S), which are abnormal in approximately $90 \%$ of the cases, provide the pivotal clue to a diagnosis of ACT. Typical imaging findings of pediatric ACT consist of a large, well-defined suprarenal tumor containing calcifications with a thin capsule and central necrosis or hemorrhage. The pathologic classification of pediatric ACT is troublesome. Even an experienced pathologist can find it difficult to differentiate carcinoma from adenoma. Surgery is the single most important procedure in the successful treatment of ACT. The role of chemotherapy in the management of childhood ACT has not been established although occasional tumors are responsive to mitotane or cisplatin-containing regimens. Because of the heterogeneity and rarity of the disease, prognostic factors have been difficult to establish in pediatric ACT. Patients with incomplete tumor resection or with metastatic disease at diagnosis have a dismal prognosis. In patients with localized and completely resected tumors, the size of the tumor has predictive value. Patients with large tumors have a much higher relapse rate than those with small tumors.

\section{Introduction}

Adrenocortical tumors (ACT) are rare in children. The first case of childhood ACT was reported in 1865 (1). Up until 1937, most children undergoing adrenalectomy for a functioning ACT would die postopera-

\section{Key words}

- Adrenocortical adenoma

- Adrenocortical carcinoma

- Adrenal gland disorders

- Pediatric cancers

- Childhood adrenocortical tumors tively due to acute adrenocortical insufficiency. When cortisone became widely available, the outcome for these patients improved dramatically (2).

Childhood ACT has peculiar clinical and biological features that contrast with those observed in other pediatric carcinomas. The 
incidence of most childhood carcinomas increases with age, whereas $65 \%$ of ACT occur in children younger than 5 years of age (3). In fact, this age distribution resembles that of tumors of embryonic origin. Moreover, most children with ACT appear healthy and usually have normal development. Finally, smaller-sized ACT can cause exuberant endocrine syndromes that often mask or delay the diagnosis (4).

In this report, we will summarize the clinical and biological characteristics and treatment outcome of children with ACT. To this end, we have reviewed information on 520 published and unpublished cases from institutions worldwide.

\section{Epidemiology}

Approximately 10,000 new cases of cancer are diagnosed each year in the United States in patients younger than 20 years. Carcinomas are rare, accounting for only 2$12 \%$ of all cancers in this age group (5-8). Adrenocortical tumors are even rarer, representing 3 to $6 \%$ of all carcinomas. In a recent report of the Surveillance, Epidemiology, and End Results (SEER) program, Lack et al. (9) found 28 cases of adrenocortical carcinomas registered between 1973 and 1987 in patients younger than 20 years. From these data, they estimated that there are 19 new cases of adrenocortical carcinomas per year in the United States in this age group. However, the true incidence of adrenocortical carcinoma may be higher. The estimated figures do not account for those cases of adrenocortical carcinomas that are misdiagnosed as adenomas, and therefore are not reported. If it is assumed that one third of all ACT are adenomas, an estimated number of 25 to 30 cases of ACT occur annually in patients under the age of 20 years in the United States.

The international incidence of ACT appears to vary substantially. Most estimates of the worldwide incidence of this pediatric neoplasm are provided by the International Agency for Research on Cancer (IARC) (10). Data from the IARC corroborate the concept that there are geographic differences in the incidence of ACT $(6-8,11,12)$. Particularly remarkable is the incidence of ACT in Southern Brazil. For example, from 1966 to 1996, 73 children under 16 years of age were admitted to the Division of Pediatric Endocrinology at the University Hospital, Federal University of Paraná, with the diagnosis of ACT (13). The University Hospital is a tertiary referral center for approximately 10 million inhabitants, 3.5 million of whom are children less than 15 years of age. With 12 to 14 new cases of childhood ACT diagnosed in the State of Paraná each year, the annual incidence of ACT within this region can be estimated to range from 3.4 to 4.2 per million children below the age of 15 years. By comparison, the annual worldwide incidence of childhood ACT ranges from only 0.3 to 0.38 per million children below the age of 15 years $(14,15)$.

Definitive explanations for this apparent excess of ACT cases in Southern Brazil are presently lacking. The Paraná region is located below the Tropic of Capricorn and has no known endemic transmissible diseases. The population is mainly of European extraction - Italy, Poland and Germany - locales in which the incidence of ACT in children has not been unduly increased. Moreover, as compared with other regions of Brazil, the southern states have had the least native Indian influence during colonization. A genetic predisposition towards cancer, which appears to play a role in many childhood tumors, is not a common feature among Southern Brazilian families of children with ACT (16). However, multiple cases of childhood ACT have been noted in some families, suggesting a possible genetic basis for this disease. Industrial pollutants, a major contributor to increased rates of solid tumor development (17), cannot be accorded more than a minor role in the Paraná cases 
due to the slow pace of industrial expansion in this region.

\section{Pathogenesis}

Predisposing constitutional genetic factors have been found in approximately $50 \%$ of children with ACT. Two genetic syndromes are clearly associated with ACT. These are Li-Fraumeni syndrome, which is associated with alterations of the tumor suppressor gene $\mathrm{p} 53$ on chromosome $17 \mathrm{p}(18,19)$ and Beckwith-Wiedemann syndrome (20), associated with alteration of the $11 \mathrm{p} 15$ region. In families with the Li-Fraumeni syndrome the frequency of adrenocortical tumor is 100 times that of the general population.

The Li-Fraumeni syndrome is a rare autosomal dominant condition with incomplete penetrance in which affected members develop many different types of tumors (2123). In addition to childhood sarcoma and pre-menopausal breast cancer, members of these families have an increased risk for the development of other malignancies, including leukemia, brain tumors, osteosarcomas and adrenocortical carcinomas (23). Other possible tumors associated with this syndrome include melanoma, carcinomas of lung, pancreas and prostate, and gonadal germ cell tumors $(19,24)$.

The relationship between environmental factors and ACT is difficult to prove. Prenatal exposure to carcinogens has been postulated as a possible etiologic factor because of early age of onset of ACT. Mann et al. (25) reported a case of a child with ACT, whose mother ingested hydroxyprogesterone hexanoate during pregnancy to prevent miscarriage. Hornstein et al. (26) described a case of adrenocortical carcinoma in a child with fetal alcohol syndrome; however, the child also had hemihypertrophy and a familial history of cancer. Consequently, factors other than alcohol could have played a role in tumor development.

\section{Clinical features}

Based on our review, children and adolescents (those younger than 20 years of age) diagnosed with ACT have a median age of approximately 3 years. Fewer than $10 \%$ of patients are 15 years or older at diagnosis. The incidence is higher among girls with the overall female/male ratio being $2.3: 1$; however, the ratio ranges from 5:1 in the 0 - to 4 year-old group to $1: 1$ in adolescents. Although the reason(s) for this prevalence in females is not understood, there is evidence of gender-specific physiologic changes in the adrenal glands (27).

The presenting manifestations of ACT depend largely on the specific tumor's secretion of adrenocortical hormones (Table 1). Hormone-secreting tumors and the associated classic endocrine syndromes (virilizing, feminizing, Cushing's and Conn's syndromes) represent the most common presentation in this age group. Although the clinical manifestations of one endocrine syndrome may predominate, ACT usually secrete several hormones and thus present signs and symptoms of multiple syndromes (mixed forms). Nonfunctional tumors, the most com-

Table 1 - Signs and symptoms of adrenocortical tumors in 58 children.

\begin{tabular}{lrr}
\hline Feature & $\mathrm{N}$ & $\%$ \\
\hline $\begin{array}{l}\text { Pubic hair } \\
\text { Hypertrophy }\end{array}$ & 53 & 91 \\
$\quad$ Clitoris & 36 & 62 \\
$\quad$ Penis & 13 & 22 \\
Acne & 42 & 72 \\
Deep voice & 32 & 55 \\
Hypertension & 32 & 55 \\
Facial hair & 29 & 50 \\
Facial hyperemia & 28 & 48 \\
Palpable tumor & 28 & 48 \\
Weight gain & 22 & 38 \\
Hirsutism & 21 & 36 \\
Moon face & 19 & 33 \\
Accelerated growth velocity & 17 & 29 \\
Centripetal fat distribution & 14 & 24 \\
Buffalo hump of the neck & 11 & 19 \\
Seizures & 7 & 12 \\
& &
\end{tabular}


mon type in adults, comprise approximately $10 \%$ of the pediatric/adolescent cases.

The virilizing syndrome was the most common presentation in this age group, corresponding to $80 \%$ of all patients in this review. The signs and symptoms could be explained by increased secretion of androgens alone, in more than half the patients. The remaining patients exhibit signs of other adrenal hormones as well. The common virilization manifestations include deepening of the voice, acne, hirsutism, increase of muscle mass and secretion and proliferation of the sebaceous glands with characteristic adult odor. In addition, gender-specific changes were noted. In females, clitoral enlargement, facial and pubic hair with male escutcheon, amenorrhea and rarely temporal balding were the most common. Corresponding signs in males include penile enlargement and precocious isosexual pseudopuberty.

Cushing's syndrome occurred in approximately one third of the patients, but only $8 \%$ of them had isolated hyperadrenocorticalism. Most of them had signs and symptoms mixed with those from virilizing syndrome. Signs and symptoms include moon facies, weight gain, centripetal distribution of fat (abdomen and upper dorsal region), plethora, hypertension, and striae.

Conn's syndrome or primary aldosteronism is commonly seen in bilateral cortical hyperplasia. Aldosterone-producing adenoma is very rare in children (28). Five patients were identified in this review comprising $1.6 \%$ of all ACT cases $(29,30)$. Only one patient was identified to have pure aldosteronism (30). Headache, weakness of proximal muscle groups, polyuria, tachycardia with or without palpitation, hypocalcemia and hypertension were the most common presenting clinical features. Like Cushing's syndrome, the signs and symptoms of Conn's syndrome can be obscured by other manifestations. Feminization was also a rare form of presentation accounting for $2.2 \%$ of the cases (31-39). The most frequent sign was gynecomastia.

The median tumor weight was $126 \mathrm{~g}$ (range, 2 to $6,000 \mathrm{~g}$ ). There was no tumor laterality predominance, with half of the cases occurring in the left and the other half in the right adrenal gland. Bilateral tumors were observed in $1.3 \%(34,40-42)$ and were rarely ectopic. Ectopic ACT was described in the spinal canal (43) and intrathoracic cavity (44). One patient had a left renal hilus tumor with no contiguity with the left adrenal gland. These findings are not surprising as ectopic adrenal cortical tissue is commonly detected retroperitoneally in the coeliac plexus, kidney, genitalia, broad ligaments, epididymis, and spermatic cord (45), which therefore act as potential sites for the development of ACT.

Children and adolescents with a functioning ACT are subject to growth disturbances (40). Pure androgen and estrogen excess most often results in increased growth rate and premature epiphyseal closure. It is not clear if this abnormal exposure to adrenal hormones will compromise the final adult height. Some investigators suggest that it will result in shorter than expected final adult height $(46,47)$. In contrast, Salt et al. (48) found a tendency to high rather than short stature in nine children treated by surgical excision of ACT. In the Curitiba series, the heights and weights of children with ACT often exceeded the 50th percentile at diagnosis (13). Patients with greater than expected heights for age included not only those with the virilizing form of ACT, but also those with the mixed form. Bone age was advanced more than 1 year in $68 \%$ of the patients. Markers of growth and development have consistently remained within the normal range in long-term survivors. In most cases, the initial predicted adult height was smaller than the target height; however, due to a "catch-down" effect that was more pronounced for bone age than for growth velocity, the final predicted adult height did not differ from the target height. True precocious puberty was noted in only one patient, 
who lacked a period of bone age catchdown.

In many instances, the increased somatic growth of these children, their generally healthy appearance, and the lack of a palpable abdominal mass diverted pediatricians from the possibility of a malignancy. The resulting delay in diagnosis can be appreciated from the long median interval (10 months; range, 3 days to 61 months) between the first clinical manifestations of ACT and its diagnosis in the Curitiba series (13). To avoid delaying diagnosis of ACT, any child less than 4 years with pubarche should be considered to have an ACT until proven otherwise. In addition, presence of acne in an infant can also be considered pathognomonic of an adrenocortical lesion (49). Finally, because Cushing's syndrome is very rare in children, it should be considered highly indicative of ACT in children younger than 10 years of age (50).

\section{Diagnosis}

Adrenocortical tumors arise from one of three adrenal cortex layers: glomerulosa, fasciculata and reticularis. It has classically been considered an epithelial tumor and therefore is classified as carcinoma or adenoma. The diagnosis of an adrenocortical tumor is made on the basis of the gross and histologic appearance of tissue obtained at surgery.

The pathologic classification of pediatric ACT is troublesome. Even an experienced pathologist can find it difficult to differentiate carcinoma from adenoma. Weiss et al. $(51,52)$ and Hough et al. (53) formulated classification systems based on macroscopic, microscopic and clinical features present at diagnosis. Bugg et al. (54) applied a modified criterion of Weiss and colleagues $(51,52)$ to analyze a large series of pediatric ACT. In this study, the adrenal tumors were divided into three groups: adrenocortical adenomas, and high-grade or low-grade carcinomas. This classification was based on the mitotic index, confluent necrosis, atypical mitoses and nuclear grade (Table 2). High-grade carcinoma and tumor weight were the most reliable predictors of outcome.

Measurements of urinary 17-ketosteroids (17-KS) frequently provide the pivotal clue to a diagnosis of ACT. 17-KS levels are elevated in the majority of the patients tested. In one review (13), 48 of the 49 patients tested positive for elevated 17-KS levels, whether their tumors caused Cushing's syndrome or virilization. Plasma dehydroepiandrosterone sulfate (DHEA-S) levels are abnormal in approximately $90 \%$ of the cases, suggesting that increase in plasma DHEA-S levels is the second most sensitive tumor marker. Abnormal urinary DHEA concentrations are less sensitive, occurring in only $2 / 3$ of the patients. Urinary 17 -hydroxycorticosteroid (17-OH) levels are elevated in cases with clinical signs of excessive glucocorticoids. In our experience, a dexamethasone suppression test was rarely necessary. The presence of elevated levels of glucocorticoid and androgen is a strong indication of an adrenal tumor.

Routine laboratory evaluation for patients suspected of having ACT includes measurement of urinary $17-\mathrm{KS}, 17-\mathrm{OH}$, and free cortisol, as well as plasma cortisol, DHEA$\mathrm{S}$, testosterone, androstenedione, 17-hydroxyprogesterone, aldosterone, renin activity, DOC and other 17-deoxysteroid precursors. This comprehensive panel of tests not only contributes to the diagnosis, but also provides useful markers for the detection of

Table 2 - Criteria for histologic diagnosis of pediatric adrenocortical neoplasms (modified from the criteria of Weiss et al. $(51,52))$.

+M itotic figures/50 high power fields. *Grade 1, mild pleomorphism; grade 2, moderate pleomorphism; grade 3, marked pleomorphism. ACA = Adrenocortical adenoma; ACC $=$ adrenocortical carcinoma.

\begin{tabular}{|c|c|c|c|c|}
\hline Diagnosis & Mitotic index ${ }^{+}$ & Confluent necrosis & Atypical mitoses & Nuclear grade* \\
\hline ACA & $0-5$ & Absent & Absent & $1-2$ \\
\hline ACC low grade & $6-20$ & Present & Present & 3 \\
\hline ACC high grade & $>20$ & - & - & - \\
\hline
\end{tabular}


tumor recurrence.

Several different imaging modalities are used to establish the diagnosis of ACT (55). Until 1982, plain radiographs, excretory urography and nephrotomograms were the principal modalities. More recently, computed tomography (CT) scan, sonogram and magnetic resonance imaging (MRI) have replaced these modalities. In the Curitiba series, 28 patients had both ultrasound and CT scan evaluations; ultrasound did not demonstrate abnormalities in 3 cases $(11 \%)$; the three tumors were detected by CT scanning. Although ultrasound examination has its limitations, it is an important modality for evaluating tumor extension into the inferior vena cava and right atrium. In our institution, the use of MRI has steadily increased over the last few years. This modality has several advantages over CT, including lack of ionizing radiation, capability of imaging multiple planes and improved tissue contrast differentiation. Moreover, recent studies have indicated that MRI may discriminate between benign and malignant lesions. Whether MRI will replace CT scanning as the first and most useful imaging procedure or provide the clinician with prognostic information remains to be determined. Presently, our recommendation is that, in addition to ultrasonogram, all patients suspected to have an adrenal tumor should be examined by $\mathrm{CT}$ scanning or MRI (55).

\section{Treatment}

\section{Surgery}

Surgery is the single most important procedure in the successful treatment of ACT. Because of tumor friability, rupture of the capsule and tumor spillage are frequent (occurring in approximately $20 \%$ of cases during the initial procedure and in $43 \%$ after local recurrence) (13). In one of the Curitiba's cases, the presenting clinical manifestations were those of an acute abdomen due to spon- taneous tumor rupture. Lack et al. (9) have reported a case of adrenocortical tumor with similar presenting features. Infiltration of the vena cava can be expected to make radical surgery difficult in some cases, although successful complete resection of the tumor thrombus has been reported in patients undergoing cardiopulmonary bypass (56). Our experience with tumor thrombi extending into the vena cava is limited to two patients. One had tumor extension into the inferior vena cava and right atrium, and was considered too ill to undergo surgery. She died one week after admission despite treatment with mitotane. The remaining child, who also had an inoperable tumor extending into the vena cava and right atrium, received two courses of combination chemotherapy (ifosfamide, carboplatinum and etoposide) without response.

Surgery requires careful and precise perioperative planning. All patients with a functioning tumor are assumed to have suppression of the contralateral adrenal gland, so that steroid replacement therapy is mandatory. Special attention to electrolyte balance, hypertension, surgical wound care and infectious complications is imperative.

\section{Chemotherapy}

The role of chemotherapy in the management of childhood ACT has not been established. Mitotane [1,1-dichloro-2-(0-chlorophenyl)-2-(p-chlorophenyl)-ethane, or o,p'DDD], an insecticide derivative that produces adrenocortical necrosis, has been used extensively in adults with ACT, but its efficacy in children is not known. Since 1990, we have been conducting a multi-institutional study to determine the efficacy and toxicity of mitotane as an adjuvant therapy for newly diagnosed children at high risk of relapse (see below). Preliminarily, mitotane has not modified the rate of relapse in this group of patients. The most important toxicities have been gastrointestinal and neuro- 
logical including nausea, vomiting, diarrhea, and abdominal pain in a high proportion of patients. Less frequent reactions included somnolence, lethargy, ataxic gait, depression and vertigo. Of interest, all prepubertal patients developed gynecomastia or thelarche. Another shortcoming of mitotane treatment is that it significantly alters steroid hormone metabolism, so that steroid measurements in blood and urine cannot be used as a marker of tumor relapse. Thus, mitotane should be considered an experimental agent in the treatment of children with ACT. Other antineoplastic drugs, including the combination of cisplatin with etoposide, 5-fluorouracil with leucovorin and ifosfamide, and carboplatinum with etoposide have been used in too few patients to permit meaningful conclusions. Adjuvant radiation therapy has not yet been evaluated in childhood ACT.

\section{Outcome}

In the Curitiba series, of the 54 patients with known outcomes, 24 (44\%) died and 30 $(56 \%)$ are disease-free for periods of 1 to 214 months from diagnosis (median, 63 months) (13). The survival rate in our series is similar to that reported by others (57).

All but two of the 24 deaths were attributable to the primary ACT. One child died from a second neoplasm (choroid plexus carcinoma), and another as the consequence of encephalopathy that developed during a hypertensive crisis. Sites of metastasis were confined mainly to the liver, lungs and regional lymph nodes. The time to tumor recurrence ranged from 1 to 48 months postsurgery (median, 6 months). Only 2 of 15 patients relapsed more than one year from the initial surgery (1.8 and 4.0 years, respectively). Recurrences were rapidly fatal in nearly all cases (median time from relapse to death, 5 months; range, 2 to 11 months). It should be noted that local relapse in these patients always preceded distant metastasis.

\section{Prognostic factors}

Because of the heterogeneity and rarity of ACT, prognostic factors have been difficult to establish. The prognostic importance of histology has been controversial $(51,52$, 54). However, none of the patients with tumor specimens classified as adenoma or benign histology (in any of the three classification schemes mentioned above) died of the disease. These findings have been corroborated in another study of 54 patients from our and two other Brazilian institutions (54). In that study, none of 11 patients with tumors of adenoma histology or diploid DNA content died from disease. However, cure was often possible for patients whose tumor specimens were classified as carcinoma or had an aneuploid DNA content (54).

In an effort to identify marginal predictors of outcome, we retrospectively analyzed 40 cases from our institution in which treatment was essentially uniform (3). The presence of metastases at diagnosis or failure to completely resect the tumor was associated with an extremely poor outcome. Among patients without metastatic disease, a univariate statistical analysis indicated that several clinical and laboratory variables had an adverse impact on outcome. These included age more than 3.5 years, interval of more than 6 months between the first symptoms and diagnosis, urinary excretion of $17-\mathrm{OH}$ $\geq 4 \mathrm{mg} \mathrm{m}^{-2}$ day $^{-1}$, tumor volume $\geq 200 \mathrm{~cm}^{3}$, and tumor weight $\geq 80 \mathrm{~g}$. Tumor size was highly correlated with a delay in diagnosis and to a lesser degree with older age, indicating that patients diagnosed more than 6 months after the first symptoms and/or older than 3.5 years tended to have larger tumors. Multivariate analysis indicated that only tumor size was independently associated with disease-free survival.

On the basis of these results, we proposed a set of staging criteria for the classification of childhood ACT (Table 3) (58). The staging criteria are highly predictive of out- 
Table 3 - Staging criteria for childhood adrenocortical tumor.

Note: Tumor spillage, defined as the rupture of the tumor capsule or breakage of a venous thrombus during surgery, does not upgrade disease stage I to stage II, provided that it was completely removed.

Stage Description

I Tumor totally excised with negative margins. The tumor weight is $\leq 200 \mathrm{~g}$, there is no evidence of metastasis and the abnormal hormone levels retum to normal after surgery.

II Tumor totally excised with negative margins. The tumor weight is $\mathbf{2 0 0} \mathrm{g}$ or there is persistence of abnormal hormone levels after surgery. Gross tumor excision with microscopic residual tumor.

III Gross residual or inoperable tumor.

IV Distant metastasis.

come among patients with either stage I or IV disease, that is $90 \%$ or more of patients with stage I disease are long-term survivors compared with $10 \%$ of those with stage IV disease (median follow-up time of 6.2 years; range of 1.4 to 13.7 years). Predicting outcome for patients with intermediate stages of disease is much more difficult. In this regard, only $52 \%$ (12 of 23 ) of the patients with stage II disease remain alive and free of disease (median 6.3 years; range 0.1 to 17.8 years). Among 4 patients with stage III disease, only one remains alive and free of disease for 6 years. This patient's tumor regressed with mitotane and subsequently could be completely excised.

In summary, two distinct prognostic groups of patients with ACT can be recognized: one with a very poor prognosis patients with metastatic disease or gross residual tumor - and another with a very good prognosis - patients with completely resected tumor of small size or adenoma histology. Together, the latter patients represent $40 \%$ newly diagnosed children with ACT.

\section{Future directions}

We are now planning a new treatment protocol for patients at high risk of relapse.
Because local recurrence is commonly the first site of relapse, we will perform careful surgical and pathological assessment of regional lymph nodes obtained at surgery. Because mitotane, as adjuvant chemotherapy, has been of little benefit, it will not be included in the initial treatment of patients whose tumors have been completely excised. For patients with local recurrence, surgery will be attempted and local radiotherapy will be considered for selected patients.

We are excited about the observations that Southern Brazilian children with ACT carry a specific germline p53 mutation (59). We plan to investigate the consequences of this molecular lesion vis-à-vis the epidemiological aspects of ACT in Southern Brazil and hope to shed light on the biology of this tumor.

Moreover, to learn more about the natural history of pediatric ACT, we have developed an international registry for this rare tumor. After informed consent is obtained, investigators register demographic, clinical, and laboratory information; follow-up data are obtained yearly. An Internet Web site (60) has been established to disseminate information about the tumor to medical professionals. 


\section{References}

1. Anonymous (1865). General melasma and short hair over the entire body of a child of three years, with conversion of the left supra-renal capsule into a large malignant tumor; the external organs of generation resembling that of adult life. Lancet, 1 : 175.

2. Hayles $A B$, Hahn HB, Sprague RG, Bahn RC \& Priestley JT (1966). Hormone-secreting tumors of the adrenal cortex in children. Pediatrics, 37: 19-25.

3. Ribeiro RC, Sandrini Neto RS, Schell MJ , Lacerda L, Sambaio GA \& Cat I (1990). Adrenocortical carcinoma in children: $A$ study of 40 cases. J ournal of Clinical Oncology, 8: 67-74.

4. Michalkiewicz EL, Sandrini R, Bugg MF, Cristofani L, Caran E, Cardoso AM, De Lacerda L \& Ribeiro RC (1997). Clinical characteristics of small functional adrenocortical tumors in children. Medical and Pediatric Oncology, 28: 175-178.

5. Young J $\mathrm{rJ}$ L, Percy $C L$, Asire AJ , Berg J W, Cusano MM, Gloeckler LA, Horm JW, Lourie J r WI, Pollack ES \& Shambaugh EM (1981). Cancer incidence and mortality in the United States, 1973-77. National Cancer Institute Monograph, 57: 1-5, 59137.

6. McWhirter WR, Stiller CA \& Lennox EL (1989). Carcinomas in childhood. A registry-based study of incidence and survival. Cancer, 63: 2242.

7. Mosso ML, Colombo R, Giordano L, Pastore G, Terracini B \& Magnani C (1992). Childhood cancer registry of the Province of Torino, Italy. Survival, incidence, and mortality over 20 years. Cancer, 69: 1300-1306.

8. Bernard J L, Bernard-Couteret E, Coste D, Thyss A, Scheiner $C$, Perrimond $H$, Mariani R, Deville A, Michel G \& Gentet JC (1993). Childhood cancer incidence in the southeast of France. A report of the Provence-Alpes-Cote d'Azur and Corsica Regions Pediatric Cancer Registry, 19841991. European J ournal of Cancer, 29A: 2284-2291.

9. Lack EE, Mulvihill JJ, Travis WD \& Kozakewich HP (1992). Adrenal cortical neoplasms in the pediatric and adolescent age group. Clinicopathologic study of 30 cases with emphasis on epidemiological and prognostic factors. Pathology Annual, 27 (Part 1): 1-53.

10. Parkin DM, Stiller CA, Draper GJ , Bieber CA, Terracini B \& Young J L (1988). International Incidence of Childhood Cancer.
N. 87. International Agency for Research on Cancer, Lyon.

11. Drut R, Hernandez A \& Pollono D (1990). Incidence of childhood cancer in La Plata, Argentina, 1977-1987. International J ournal of Cancer, 45: 1045-1047.

12. Marigo C, Muller H \& Davies J NP (1968). Survey of cancer in children admitted to a Brazilian charity hospital. J ournal of the National Cancer Institute, 43: 1231-1240.

13. Sandrini $R$, Ribeiro $R \&$ DeLacerda $L$ (1997). Extensive personal experience: childhood adrenocortical tumors. J ournal of Clinical Endocrinology and Metabolism, 82: 2027-2031.

14. Hisada M, Garber J E, Fung CY, Fraumeni J r JF \& Li FP (1998). Multiple primary cancers in families with Li-Fraumeni syndrome. J ournal of the National Cancer Institute, 90: 606-611.

15. Stiller CA (1994). International variations in the incidence of childhood carcinomas. Cancer Epidemiology, Biomarkers and Prevention, 3: 305-310.

16. Sandrini R, Pianovski MA, Gabardo J , Fernandes J S, Magdalena NI, De Lacerda L \& Ribeiro RC (1996). Childhood adrenocortical tumor (ACT) in Southem Brazil: lack of association with familial cancer syndromes. Proceedings of the 10th International Congress of Endocrinology/ 78th Endocrine Society Meeting. San Francisco, CA, USA. Vol. II of Program and Abstracts, 921.

17. Kristensen $P$, Andersen A, Irgens LM, Bye AS \& Sundheim L (1996). Cancer in offspring of parents engaged in agricultural activities in Norway: incidence and risk factors in the farm environment. International J ournal of Cancer, 65: 39-50.

18. Li FP \& Fraumeni J r J F (1969). Rhabdomyosarcoma in children: epidemiologic study and identification of a familial cancer syndrome. J ournal of the National Cancer Institute, 43: 1365-1373.

19. Li FP, Fraumeni J rJ F, Mulvihil J J, Blattner WA, Dreyfus MG, Tucker MA \& Miller RW (1998). A cancer family syndrome in twenty-four kindreds. Cancer Research, 48: 5358-5362.

20. Wiedemann HR (1964). Complexe malformatif familial avec hernie umbilicale et macroglossie, un "syndrome nouveau". J ournal de Genetique Humaine, 13: 223.

21. Birch J M (1994). Li-Fraumeni syndrome. [Review]. European J ournal of Cancer, 30A: 1935-1941.

22. Hartley AL, Birch J M, Marsden HB, Reid
H, Harris M \& Blair V (1987). Adrenal cortical tumors: epidemiological and familial aspects. Archives of Disease in Childhood, 62: 683-689.

23. Srivastava S, Zou ZQ, Pirollo K, Blattner W $\&$ Chang EH (1990). Germ-line transmission of a mutated p53 gene in a cancerprone family with Li-Fraumeni syndrome. Nature, 348: 747-749.

24. Malkin D, Li FP, Strong LC, Fraumeni J r J F, Nelson CE, Kim DH, Kassel J, Gryka MA, Bischoff FZ \& Tainsky MA (1990). Germline p53 mutations in a familial syndrome of breast cancer, sarcomas, and other neoplasms. Science, 250: 12331238.

25. Mann J R, Cameron AH, Gornall P, Rayner PH \& Shah KJ (1983). Transplacental carcinogenesis (adrenocortical carcinoma) associated with hydroxyprogesterone hexanoate. Lancet, 2: 580.

26. Hornstein L, Crowe C \& Gruppo R (1977). Adrenal carcinoma in a child with history of fetal alcohol syndrome [Letter]. Lancet, 2: 1292-1293.

27. Wiesenfeld P \& Michaelis OE (1994). Gender differences in adrenal cortex steroid production in SHR/N-corpulent rats. Proceedings of the Society for Experimental Biology and Medicine, 207: 254-259.

28. Kafrouni G, Oakes MD, Lurvey AN \& De Quattro V (1975). Aldosteronoma in a child with localisation by adrenal vein aldosterone: collective review of the literature. J ournal of Pediatric Surgery, 10: 917-924.

29. Sandrini R (1995). Study of adrenocortical tumors in children. Doctoral thesis, University Hospital, Federal University of Paraná, Curitiba, PR, Brazil.

30. Streeten DHP, Tomycz N \& Anderson GHJ (1979). Reliability of screening methods for the diagnosis of primary aldosteronism. American J ournal of Medicine, 67: 403-413.

31. Stembach MS, Miller JD \& Chevalier L (1983). Childhood multiple endocrine neoplasia, medullary thyroid carcinoma, pheochromocytoma and adrenal cortical carcinoma: $\mathrm{MCH}$ experience. In: Humphrey GB, Grindey GB, Dehner LP, Acton RT \& Pysher TJ (Editors), Adrenal and Endocrine Tumors in Children. 1st edn. Martinus Nijhoff Publishers, Boston, 331-341.

32. Weatherby RP \& Carney J A (1983). Pathologic features of childhood adrenocortical tumors. In: Humphrey GB, Grindey GB, Dehner LP, Acton RT \& Pysher TJ (Editors), Adrenal and Endocrine Tumors in 
Children. 1st edn. Martinus Nijhoff Publishers, Boston, 217-248.

33. Lefevre $M$, Gerard-Marchant $R$, Chaussain J L \& Lemerle J (1983). Adrenal cortical carcinoma in children: 42 patients treated from 1958 to 1980 at Villejuif. In: Humphrey GB, Grindey GB, Dehner LP, Acton RT \& Pysher TJ (Editors), Adrenal and Endocrine Tumors in Children. 1st edn. Martinus Nijhoff Publishers, Boston, 265-276.

34. Holcombe J H, Pysher TJ \& Kirkland RT (1983). Functioning adrenocortical tumors in childhood. In: Humphrey GB, Grindey GB, Dehner LP, Acton RT \& Pysher TJ (Editors), Adrenal and Endocrine Tumors in Children. 1st edn. Martinus Nijhoff Publishers, Boston, 277-290.

35. Herlin $P$, Herbaux $B$, Huillet $P$, Hanus $T \&$ Debeugny $P$ (1986). Le corticosurrénalome de l'enfant. A propos de 3 cas et revue de la littérature. Chirurgie Pediatrique, 27: 162-164.

36. Calzi P, Bertanza C, Gargantini L \& Bianchi C (1987). Neoplasia surrenalica in eta pediatrica. Descrizione di un caso clinico e review della letteratura. Pediatria Medica e Chirurgica, 9: 621-626.

37. Halmi KA \& Lascari AD (1971). Conversion of virilization to feminization in a young girl with adrenal cortical carcinoma. Cancer, 27: 931-935.

38. Itami RM, Admundson GM, Kaplan SA \& Lippe BM (1982). Prepubertal gynecomastia caused by an adrenal tumor. Diagnostic value of ultrasonography. American J ournal of Diseases in Children, 136: 584586.

39. Leditschke J F \& Arden F (1974). Feminizing adrenal adenoma in a five-year-old boy. Australian Paediatric J ournal, 10: 217-221.

40. Hauffa BP, Roll C, Muhlenberg R \& Havers W (1991). Growth in children with adrenocortical tumors. Klinische Paediatrie, 203: 83-87.

41. Ranew RB, Meadows AT \& D'Angio GJ (1983). Adrenocortical carcinoma in children: experience at the Children's Hospital of Philadelphia, 1961-1980. In: Humphrey GB, Grindey GB, Dehner LP, Acton
RT \& Pysher TJ (Editors), Adrenal and Endocrine Tumors in Children. 1st edn. Martinus Nijhoff Publishers, Boston, 303-305.

42. Loridan L \& Senior B (1969). Cushing's syndrome in infancy. J ournal of Pediatrics, 75: 349-359.

43. Kepes J J , O'Boynick P, J ones S, Baum D, McMillan J \& Adams ME (1990). Adrenal cortical adenoma in the spinal canal of an 8-year-old girl. American J ournal of Surgical Pathology, 14: 481-484.

44. Medeiros LJ , Anasti J, Gardner KL, Pass HI \& Nieman LK (1992). Virilizing adrenal cortical neoplasm arising ectopically in the thorax. J ournal of Clinical Endocrinology and Metabolism, 75: 1522-1525.

45. Page DL, DeLellis RA \& Hough AJ (1986). Embryology and postnatal development. In: Page DL, DeLellis RA \& Hough AJ (Editors), Tumors of the Adrenal. 2nd series edn. Armed Forces Institute of $\mathrm{Pa}$ thology, Washington, DC, 25-35.

46. Lee PD, Winter RJ \& Green OC (1985). Virilizing adrenocortical tumors in childhood: eight cases and a review of the literature. Pediatrics, 76: 437-444.

47. Zaitoon MM \& Mackie GG (1978). Adrenal cortical tumors in children. Urology, 12: 645-649.

48. Salt AT, Savage MO \& Grant DB (1992). Growth patterns after surgery for virilising adrenocortical adenoma. Archives of Disease in Childhood, 67: 234-236.

49. Stewart DR, Morris-J ones PH \& J olleys A (1974). Carcinoma of the adrenal gland in children. J ournal of Pediatric Surgery, 9: 59-67.

50. Gilbert MG \& Cleveland WW (1970). Cushing's syndrome in infancy. Pediatrics, 46: 217-229.

51. Weiss LM, Medeiros LJ \& Vickery J r AL (1989). Pathologic features of prognostic significance in adrenocortical carcinoma. American J ournal of Surgical Pathology, 13: 202-206.

52. Weiss LM (1984). Comparative study of 43 metastasizing and nonmetastasizing adrenocortical tumors. American J ournal of Surgical Pathology, 8: 163-169.
53. Hough AJ, Hollifield JW, Page DL \& Hartmann WH (1979). Prognostic factors in adrenal cortical tumors: A mathematical analysis of clinical and morphologic data. American J ournal of Clinical Pathology, 72: 390-399.

54. Bugg MF, Ribeiro RC, Roberson PK, Lloyd RV, Sandrini R, Silva J B, Epelman S, Shapiro DN \& Parham DM (1994). Correlation of pathologic features with clinical outcome in pediatric adrenocortical neoplasia. A study of a Brazilian population. Brazilian Group for Treatment of Childhood Adrenocortical Tumors. American J ournal of Clinical Pathology, 101: 625629.

55. Ribeiro J , Ribeiro R \& Fletcher B (2000). Imaging findings in pediatric adrenocortical carcinoma. Pediatric Radiology, 30: 4551.

56. Godine LB, Berdon WE, Brasch RC \& Leonidas J C (1990). Adrenocortical carcinoma with extension into inferior vena cava and right atrium: report of 3 cases in children. Pediatric Radiology, 20: 166-168 (Discussion 169).

57. Chudler RM \& Kay R (1989). Adrenocortical carcinoma in children. Urologic Clinics of North America, 16: 469-479.

58. Sandrini R, De Lacerda L, Sampaio G, Sabbaga C, Schmit-Lobe MC, Roberson P, Cat I \& Ribeiro R (1993). Adrenocortical tumors in children: Relationship between disease stage and outcome. Pediatric Research, 33: S22.

59. Ribeiro $R$, Sandrini $F$, Figueiredo $B$, Zambetti G, Lafferty A, DeLacerda L, Rabin M, Cadwell C, Sampaio G, Cat I, Stratakis CA \& Sandrini R (2000). Childhood adrenal cortical tumors (ACT) in southern Brazil are associated with a novel germline tp53 mutation. Proceedings of the American Society of Clinical Oncology, 19: 588a (Abstract 2314).

60. Saint J ude Children's Research Hospital. Adrenocortical Tumor Registry [Online]. Last updated J anuary, 2000. [http:// www.stjude.org/ipactr/default.htm]. Accessed J une 1, 2000. 